\title{
PLANNING FOR SUSTAINABLE DEVELOPMENT AND ENVIRONMENTAL PROTECTION IN POST-CONFLICT PHASE - CASE STUDY: SYRIA
}

\author{
Batoul Ibrahim, Vojtech Novotny \\ Czech University of Life Sciences Prague, Czech Republic \\ ibrahimb@fzp.czu.cz, novotnyvoj@fzp.czu.cz
}

\begin{abstract}
Syria is a semiarid country suffering from lack of water sources and environmental degradation, as a developing nation, its economy depends basically on agriculture and fossil fuel. Before the crisis, there were some challenges in the urban environment. The unsustainable use of water was expected to negatively affect the population growth. At the same time, the demand for water was increasing because of rapid urbanization, which led to water scarcity challenge. During the conflict the challenges increased, especially with the internal displacement of people, who fled their towns to safer areas to avoid hostilities, such challenges are mainly the lack of potable water, the increased solid waste production, which led to more pressure on daily garbage collection, and the lack of proper sanitation and typically dispose of sewage in the growing informal settlement areas; this increase of daily discharge had deepened both environment and hygiene hazards. This paper is an attempt to first, describe the environmental situation in Syria before and during the conflict, second, to describe the neglected attitude of people toward environment and what the impact was of such attitude and finally, to discuss the role of planning as a main factor in protecting the environment after the conflict ends and what procedures should be considered in this regard.
\end{abstract}

Keywords: Syria, planning, environment, sustainability, conflict.

\section{Introduction}

Syria is a semiarid Mediterranean country suffering from lack of water sources and environmental degradation. As a developing nation, its economy depends basically on agriculture and fossil fuel. Prior to 2011, there were some challenges in the urban environment. These challenges were exacerbated by the ongoing conflict, and pointed to the problematic areas that need to be addressed in the reconstruction phase. This paper is structured as follows: first, a review of Syrian environmental situation is made by illustrating the environmental challenges for urban areas and revising the environmental policy in Syria. Second, the new challenges that emerged during the crisis are addressed. Finally, how to connect planning to sustainable environment that benefit of the latest academic researches regarding sustainable development and environmental challenges in Syria with focus on the role of planning in environmental sustainability and what the needed procedures are that could be suggested.

\section{Methodology}

The main objective of this paper is to address the fundamental principles that need to be considered within planning with relation to sustainable development and environmental protection in post-conflict phase and thus open further discussion to more deep and empirical researches in the future. Therefore, the methodology of this paper will be based on reviewing the environmental situation in Syria including statistical data about environmental challenges before and after the current crisis; in addition to review the environmental law and the most important procedures made by Syrian government in this respect. And as the result of this review - to define the important planning requirements regarding sustainable development and its important measurements and dimensions as a response to the addressed challenges in the post conflict phase and to discourse what is expected from planning in relation to basic environmental aspects.

\section{Pre-Conflict Situation}

In Syria because of the rural-urban emigration caused by environmental degradation, 38 percent of the total population lived in informal settlements and, in Damascus alone, informal settlements were growing at 40 to 50 percent per year. In 2010, the urban population (which counts in total for more than 50 percent from Syrian total population) was estimated by 11,754 thousand people, while the slum proportion prevalence in 2005 was 10.5 percent [1]. The roots of migration issue come from rural areas, it was the result of water scarcity (water (un)availability is the most important danger to sustainability of rural areas), land fragmentation (the rural tradition of splitting the land between the 
sons of the farmer, this has led to ever-smaller farm sizes and subsequent decreased average crop yield per farm), and crop failure that pushed the farmers to migrate. In 2010 alone, 50,000 rural families left their homes to seek prosperity in big cities [2], increasing the competition for homes, jobs, water and land in the receiving communities. The combined pressure of droughts and growing population has already been bearing its poisonous fruits. 75 percent of farmers faced total crop failure in 2011, causing 800,000 Syrians to lose their livelihood and rendering another 1,000,000-food insecure [3].

Besides migration issue, there were some challenges in the urban environment. The unsustainable use of water was expected to affect negatively the population growth. At the same time, the demand for water was increasing because of rapid urbanization, which led to a water scarcity challenge. Therefore, there was a need to increase wastewater treatment for agricultural purposes in order to reduce demands for freshwater [1].

The Ministry of State for Environmental Affairs (here-in-after MSEA) pointed on the following dangers to sustainable development of the Syrian society for the years of 2001 to 2010 [4]:

- Increased rates of population and economic growth leading to a greater demand for drinking quality water exceeding the capacity of water resources and wastewater treatment plants. The effects of that account for the deterioration of both quantity and quality of aquatic ecosystems;

- Water intensive agriculture that accounted for $89 \%$ of water used overall and its influence on depleting groundwater resources;

- The increasing risk of catastrophic droughts;

- Increasing fragmentation of agricultural land ownership.

The government of the Syrian Arab Republic (here-in-after GoS) responded by approving a set of measures aimed at increasing sustainability of the society. Nevertheless, the effects of these measures proved not being strong and fast enough. According to the data from the Central Bureau of Statistics, in Homs and Aleppo, the two greater Syrian cities that received the bulk of the immigration of poor rural families, the share of illegal (informal) housing stock amounted to 59 percent and 39 percent of total housing stock respectively. This implies that almost three out of five families in Homs and more than a third of families in Aleppo lived in neighborhoods deprived of proper sanitation as well as other basic public services [5].

The development of the urban legislations and their updates are very important to perform the visions, policies and orientations of the general master plans, which are established with advanced mechanisms that achieve their development goals. The success of these urban legislations is subject to the building of a unified and comprehensive legislation for urban development and urban renewal. Consequently, the impressive results of giving transparency, the ease of urbanism sector management and the harmony in meeting the current and future needs that are emerged from this comprehensive legislation will put the foundations to build sustainable communities according to the set plans.

The GoS issued the Decree-Law No. 26 for the year 2016 "regional planning law", which settles the regional planning law acts; it also includes the requirement to establish the Regional Planning Commission (RPC). Additionally, it presents the solutions to the problems that emerged from the rapid growth of cities through scientific and technical approaches in order to achieve a "regional stable development" for rural and urban areas in the country.

Moreover, within the tenth five-year-plan (2006-2010) - which is a comprehensive national plan that addresses development issues in all sectors such as economy, environment, social, planning, health, and education - one of the main objectives was to achieve the sustainable and stable regional development, establish development projects related to sustainable development management for both rural and urban areas in Syria, and building the regional local capitals/ metropolises as poles of balance on the national level project [6]. The environmental aspect has also been an essential part of the subsequent 11th five-year plan.

Furthermore, the environmental dimension has been enforced in the public policies planning processes; therefore; the environmental dimension was embedded in the action of several ministries, for example, the concept of sustainable use of the natural resources was included within the tasks of the related ministries that are responsible for natural resources management, i.e. the Ministry of Agriculture and Agrarian Reform, the Ministry of Irrigation and Water Resources, and the MSEA. 
Several legislations were issued to support the environmental protection, such as the legislation that enforces taxes on cars, the establishment of environmental protection fund, reducing fees on hybrid cars, and small loans and facilitations for people, who would adopt water heating by solar energy. Moreover; Decree-Law No.12 for the year 2012 "The Environmental Protection Law" was issued as an alternative to all its precedent laws. The main objective of this law is to establish the basic rules of environmental safety and protection from pollution and to achieve environmental development. This law addresses the tasks that are entrusted to the MSEA, the principles and rules of environmental inspection, the establishment of The Supreme Council for Environmental Protection and identifying its tasks, responsibilities and sanctions; in addition to the tasks that should be made by the Ministry in cooperation with competent authorities in order to follow the implementation of provisions of this law and all other legislations and acts related to the environmental affairs in order to achieve the intended objectives.

\section{Post-Conflict Phase}

Recently, the country has fallen under severe conflict that affected all areas of living. Infrastructure is being destroyed and many people have escaped their homes and fled away. There are around 11,827,054 Syrians who left their home, of which around 4,194,554 have left the country and around 7,632,500 people are internally displaced [7]; Fig.1.

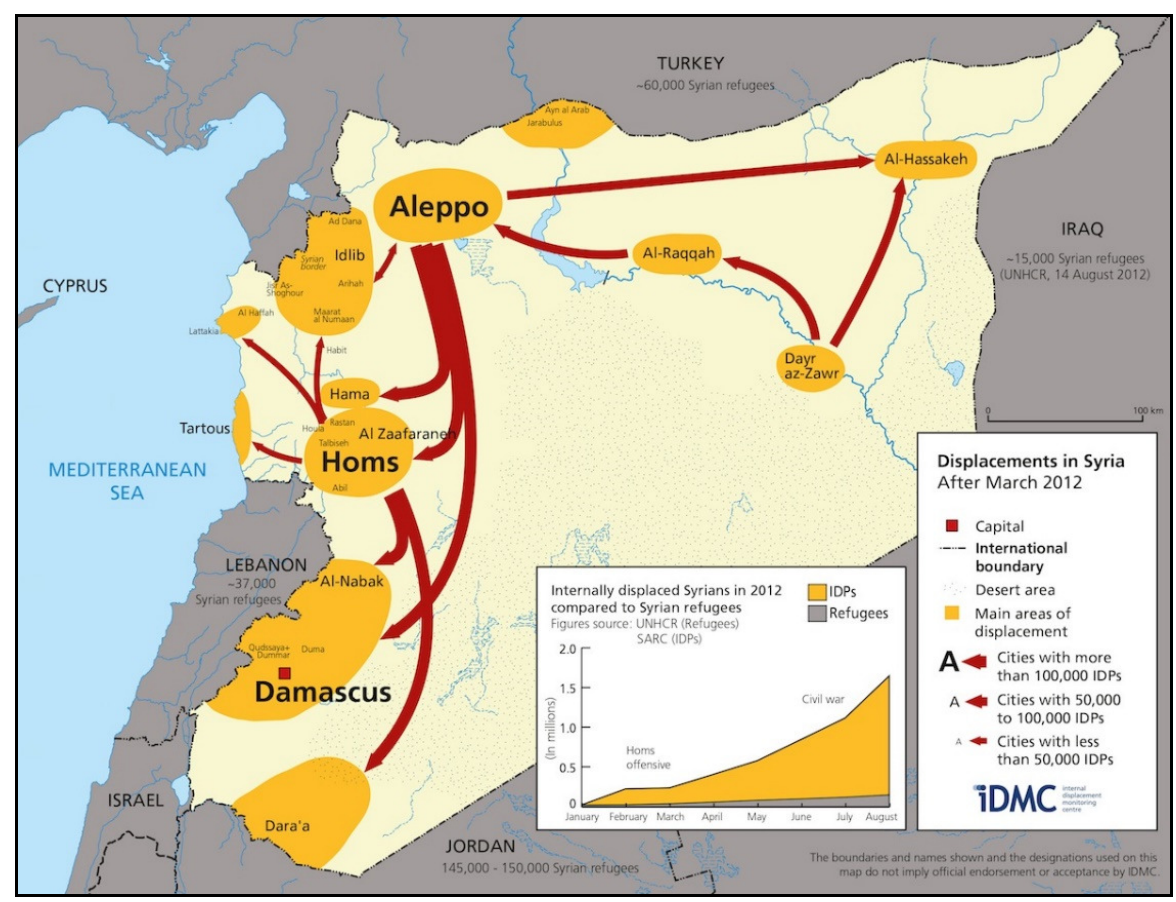

Fig. 1. Main flows of IDPs, source: The Internal Displacement Monitoring Centre (SW), (2012) http://www.internal-displacement.org/middle-east-and-north-africa/syria/2012/displacements-in-syriaafter-march-2012

The ongoing civil war in Syria influences heavily the way of living of the population locked in the conflict zones as well as the population safe behind the frontline. On the one hand, the relatively safe areas receive ever-growing number of people fleeing the unlivable conditions on the battlefield. On the other hand, the different cities of pre-war Syria specialized to produce and supply different products that the Syrian population needed. Having lost multiple important cities (Deir Ezzor, Rakka, and large parts of Aleppo among others) it is the population of the cities left under government control that has to take over their former roles.

The escape of so many people to the relatively "safe" cities has led to more pressure on urban services, such as housing, electricity, potable water, fuel supply, transportation and such. A large percentage of internal refugees came to the cities' suburbs that are increasing currently with an absence of good planning that considers sustainability measures [8]. Even though there was a huge focus on the expansion of suburbs before the crisis, this expansion formed another pressure on the 
cities (namely Damascus and Lattakia), as most people living in suburbs worked in the city centre, which means that the population density is at its highest in the day hours. Additionally, there were problems of transportation and daily commuting to the city that could be added to the lack of services in these areas [9]. Similar is the effect of the increased population on electricity and water supply, sanitation and waste disposal. The solid waste production by the population has doubled over the period to 850 tons per day requiring three more makeshift waste dumps to be established, while electricity is available for three hours in a six hours rotation and drinking water for no longer than four hours a day.

At the same time, the overall agricultural production of the Latakia region has severely decreased, mostly because of complicated security situation in the rural areas (parts of the rural Latakian region are a stage for direct armed clashes between the governmental and opposition forces, which stay behind the total destruction of nearly 50 percent of the Frunlok Natural Reservation and probably the burned 10,000 ha of forests as well) [5]. Moreover, the government launched the WASH (Water, Sanitation and Hygiene) program [2]. The WASH program focused on the most acute problems to sustain the healthiness of exploding populations of the (relatively) safe cities. In a situation similar to European $19^{\text {th }}$ century industrial cities, providing safe water supply, waste disposal, wastewater treatment and energy to cities populations (especially those living in informal settlements) became almost unsurpassable challenge.

\section{The Role of Planning and the Required Procedures}

In all reconstruction projects, none of the urban sustainability considerations were measured. The objectives of these projects focused on emergency needs of people. Thus, it is beneficial to see the Syrian conflict as an opportunity to achieve sustainable development and understand the structural problems that face the sustainable planning. Therefore, it is very important to have appropriate methods to use and rehabilitate the remaining resources toward the recovery phase. For this purpose, several recommendations were proposed, for example:

- It is important to give the priority to agricultural lands within the master plan schemes and that will happen by rehabilitation of these lands after the conflict ends;

- Restriction and limitation of construction, especially on the productive agriculture areas, which will help in creating healthy and appropriate environment, self-sufficiency and job opportunities for the locals;

- Increasing the public green spaces;

- Recycling the rubbles in order to use them in the reconstruction process and that will help in saving the costs, transportation and time [10].

The rapidly increased challenges of urban sprawl require fast and cooperative response in all aspects, national, regional and global ones; in order to keep the cities as habitats that support the economic growth and prosperity for people with sustainable environmental patterns. Ahmadi \& Toghyani [11] concluded that government and management, technology and livelihood are the three basic levels of all social levels that need essential changes to pursue urban sustainability. However, the unprecedented expansion of informal settlements especially on the city fringe; in addition to urban sprawl toward agricultural lands had threatened water resources and the scarce natural resources; and strained the urban infrastructures, which made them unable to absorb the increased demand on services.

As sustainable development has its goal to eliminate the negative effects of environmental pollution; policies for sustainable development must be based on an assessment of available evidence. Therefore, it is important to depend on wise and resilient urban planning (which is considered as the main factor for this process). The importance of urban planning in fulfilling the environmental sustainability is related to the land use planning process, because it helps improving the environment. Furthermore, Säynäjoki, et al. [12] found that environmental assessment leads the decision making in urban planning and that through considering the environment as part of the city political strategy agenda not as a contradiction of the municipalities decision making process. Also making a comprehensive study/evaluation regarding environmental impact assessment will help in determining the threshold capacity of environment. 
This highlights the reasons that environmental sustainability should be assessed in urban planning; it is because this method provides environmental knowledge to all stakeholders, who are involved in the decision-making process; and promotes more sustainable environmental alternatives. Eventually, the long-term objective of future sustainable communities will be pursued through applying consumption base approach in land use environmental assessment, which will lead to a better measurement of environmental sustainability [13]. It is worth mentioning that the European Community Commission Guide (1992) indicated the importance of using the environmental issues and the environmental capacity tools to form the base that will support the development plans. "Considering the limited potential and power of ecological context of cities, urban sustainable development would be possible if it is based on the local and environmental characteristics in the same format and observing the fundamental principles of sustainable development" [12].

For this aim, measuring the ecological footprint will provide a basic idea to know how much land we need to support the consumption needs for citizens of the city. This can be achieved by applying methods developed by Rees [13], which is an estimated calculation of land and water that people require/use to meet their needs based on the calculation of sum of waste and resources flow. The aim of this approach is to illustrate the impact on resources and ecosystems that are caused by the cities, "the idea that somewhere the ecological load of a city's consumption has to be borne" [14].

However, the physical dimension of sustainable settlement is important to consider, for instance, the use of recycled building materials that have resulted from destroyed buildings will help in minimizing the damages to environment by reproducing these building materials. Also, it is necessary to have an integrated vision to redesigning the transportation system and providing public facilities with least amount of natural resources exploitation during the rehabilitation of damaged infrastructure. Furthermore, planning should consider the increased population density, which probably will be an issue when the exiled return and decide to live in the city and not go back to their towns; this might be achieved through a detailed study of the quantity, concept and distribution of the density within the urban space. Moreover, it is essential to pay attention to the spatial planning scale, for instance, applying productive ecosystem on the fringe of urban areas or surrounding them, to areas that absorb and degrade the human waste and sewage, balanced distribution of public amenities, and use of multipurpose spaces

Beside the footprint measurement, planning should consider the virtual water measurement as it gives more clearance to understand the environmental burdens. Furthermore, calculation of sustainable standards (green spaces, resources efficiency use, renewable energy, sanitation, green economy and such) depending on certain dimensions such as the flow of resources, urban environment quality and the influence of transportation and user pattern on landscape will provide a useful measurement tool for sustainable urban planners, when it is well-adjusted with a relation to places and cities [11]. Therefore, reforming the planning regulations and methods is essential in this process. In addition, to encouraging the involvement of different groups of people (locals, NGOs, stakeholders, planners, designers...etc) simultaneously with participation of all planning institutions (on regional and national level) that will be involved in rebuilding Syria and increasing the bottom-up decision-making process will help in better understanding, awareness and implementation of environmental sustainability objectives [15].

As sustainable development helps strengthening the environmental life; a flexible framework that takes a broad perspective on the environmental sustainability of urban areas and considers the environmental impact of all consumption should be adopted and that requires different forms of strategies, methods, tools. Ahmadi \& Toghyani [11] suggested that a wise use of natural resources simultaneously with dynamic protection of them will ensure a better quality of life of people and future generations; therefore, the continuation of biodiversity systems whether for the city, towns, villages should be assisted by the strategies of urban sustainable development.

\section{Conclusions}

It is necessary to address sustainable environmental development in order to delimitate the rapid unplanned growth of the cities and its disastrous consequences for the environment and society in addition to pollution, climate change, scarcity of materials and urbanization. The augmented importance of converting urban areas into sustainable communities points out to the significant role of 
urban planning in addressing environmental challenges that arise continuously in cities; taking into consideration all aspects (economic, social, cultural, physical, environmental, management....etc) in parallel with a detailed study to inspect urban sustainability indicators and use it as tools to assess the needed procedures to pursue environmental and urban sustainable development.

This paper illustrates how important it is to introduce the environmental challenge in order to address the needed expectations from planning, when dealing with the protection of environment and sustainable development in post conflict phase especially that in all reconstruction projects, none of the urban sustainability considerations were measured; and thus pave the way to future researches to be more improved toward actual implementation and perhaps to adapt some environmental successful experiences from neighbouring countries.

\section{References}

[1] UN-Habitat. The State of Arab Cities 2012 / 2013: Challenges of Urban Transition. 2nd edition. Nairobi, Kenya: 2012.

[2] United Nation (UN). Syria Regional Response Plan: Strategic Overview, 2014.

[3] Erian W .,Katlan B, Badah O. Global Assesment Report in Disaster Risk Reduction (GAR). Drought Vulnerability in the Arab Region: Special Case Study: Syria, 2011.

[4] Ministry of State for Environmental Affairs (MSEA) Report. The Status Quo Analysis of the Environment in Syria, 2011. (In Arabic).

[5] UN-Habitat, Swiss Agency for Development and Cooperation (SDC). City Profile: Latakia: Multi Sector Assessment, JUNE, 2014.

[6] Maya R. The Urban Planning in Syria and the Contemporary Direction Toward Sustainable Urban Development. Damascus University Journal of Engineering Sciences, vol. 26:1, 2010, pp.269295. (In Arabic).

[7] UNHCR. 2015 UNHCR country operations profile - Syrian Arab Republic, 2015. [online] [16.02.2016]. Available at: http://www.unhcr.org/pages/49e486a76.html.

[8] Ahmad L. Reshaping Suburbs in the Framework of Sustainable Environmental Neighborhoods. Paper presented in the 1st engineering conference on "Development Priorities and Reconstruction", August 16-18, 2015, Lattakia, Syria. (In Arabic).

[9] Gada A., Maya R. Suburbs: a Planning Solution for Population Increase or a New Urban Problem?. Damascus University Journal of Engineering Sciences, vol. 29:2, 2013, pp. 567-582. (In Arabic).

[10] Atfeh N, Kanjarawi R, Mrad L, Jabbour L, Roux JM.. The Role of Universities in Time of Crisis. A Workshop Paper- Vision on the Educational Cooperation Project 'Planning for Syria' between Damascus University, Grenoble University Alps, Grenoble Institute of Planning, Mundos Urbano Master Programme and Urban Engineering and Sustainable Development Master. 61p, 2015.

[11] Ahmadi F., Toghyani S. The Role of Urban Planning in Achieving Sustainable Urban Development. OIDA International Journal of Sustainable Development, vol. 2, 2011, pp. 23-26.

[12] Säynäjoki E.-S., Heinonen J., Junnila S. The Power of Urban Planning on Environmental Sustainability: A Focus Group Study in Finland. Sustainability, vol. 6, 2014, pp. 6622-6643.

[13]Rees W. Ecological footprints and carrying capacity: what urban economics leaves out. Environment \& Urbanization, vol. 4, 1992, pp. 121-130.

[14] Lynch K. 2004. Managing Urbanism. In Harris, F (eds) Global Environmental Issue. England: John Wiley \& Sons Ltd, 2004, pp. 195-228.

[15] Barakat T. Activating the Role of Popular Participation and Sustainable Enablement in Local Development. Tishreen University Journal for Research and Scientific Studies - Engineering Sciences Series, vol.36:5, 2014, pp. 63-82. (In Arabic). 